\title{
Managing technology development teams - exploring the case of microsytems and nanosystems
}

\section{Norbert Burger ${ }^{1,3}$, Thorsten Staake ${ }^{1}$, Elgar Fleisch ${ }^{1,2}$ and Christofer Hierold ${ }^{3}$}

\author{
${ }^{1}$ Chair of Information Management, ETH Zurich, CH-8092 Zurich, Switzerland. nburger@ethz.ch; \\ tstaake@ethz.ch \\ ${ }^{2}$ Institute of Technology Management, University of St. Gallen, CH-9000 St. Gallen, Switzerland. \\ elgar.fleisch@unisg.ch \\ ${ }^{3}$ Micro and Nanosystems Group, ETH Zurich, CH-8092 Zurich, Switzerland. chierold@ethz.ch
}

\begin{abstract}
New sensor and actuator concepts based on microelectromechanical systems (MEMS) and nanoelectromechanical systems (NEMS) are increasingly being developed from lab status toward commercialization. The associated technology development for the provision of improved functionalities and cost reduction often requires highly interdisciplinary development teams where scientists and engineers from different disciplines closely work together. Managing these teams is a key challenge for MEMS/NEMS organizations. This research examined eight technology developments in MEMS/NEMS in international companies. Based on in-depth interviews with innovators, we explored the managerial aspects of development teams. We identified and discuss (1) leadership, (2) market, (3) team structure and culture, (4) innovation motivation, (5) innovation driver, (6) experience and know-how, and (7) product vision and innovation strategy as key influences on teams in the early development phases of MEMS/NEMS. Our study reveals that integrative and manufacturing know-how and capabilities are the most critical capacities to be developed by the team from the idea to the concept phase. The team's lived experience during long development times from 5 to 10 years or more may allow a fast response to changes from market and technology (e.g. materials and nanotechnology). The results indicate that the process of how know-how and capabilities are created by the team is more important than the mere existence of specific expertise.
\end{abstract}

\section{Introduction}

$\mathrm{T}$ echnology development teams in microelectromechanical systems/nanoelectromechanical systems (MEMS/NEMS) companies work on new concepts to reduce costs through miniaturization and a decrease of material consumption (Vigna, 2009; Burger and Staake, 2010). A positive side effect is that more functionality and higher performance can be integrated on the same or smaller footprint (Hierold, 2004; Fujita, 2007; Petersen, 2010; Polla, 2010). However, the capital-intensive nature of 
technology developments based on materials and nanotechnology require technological and managerial innovation for successful commercialization (Eijkel et al., 2006; Maeda et al., 2007; Maine, 2008; Newbert et al., 2008; Avila-Robinson and Miyazaki, 2011; Walsh and Linton, 2011).

This study is embedded into the frame of activities of a microtechnology and nanotechnology competence center fostering collaboration and technology transfer between academia and industry. The investigation focuses on innovators' experience from MEMS/NEMS companies, discussing major positive and negative influences on technology development teams in the early phases of the innovation process. For the development of complex product or process concepts such as in MEMS/NEMS, teams with crossfunctional members from a variety of functions are used to enhance developments (Walsh et al., 1996; Barczak and Wilemon, 2003; Gebert et al., 2006; Hage et al., 2008; Maine, 2008; Newbert et al., 2008). The technology itself is of a highly interdisciplinary character, requiring expertise from different basic and engineering sciences at once (Walsh, 2002; Polla, 2010).

Projects with developments of fundamental new products and technologies are long, costly, and also bear its risks of failure (Abernathy and Clark, 1985; Utterback, 1994; Christensen, 1997; Spencer et al., 2008). However, technology projects are growth engines providing platforms for the next generation of products and processes (Cooper, 2006). Even though the roots of MEMS processes can be found in mainstream silicon process technologies, standardized manufacturing methods have only a limited applicability. Only a few standards in manufacturing are available, and most products need specialized process technologies (Tadigadapa and Najafi, 2003; Merz et al., 2009; Tierney and Walsh, 2009). Thus, expectations on development teams go far beyond developing innovative new technology concepts. MEMS/NEMS project teams are intended to provide unique knowledge and capabilities to the company that will provide long-term sustainable competitiveness (Coates and McDermott, 2002; McDermott and O'Connor, 2002; Newbert et al., 2008).

In many studies of development teams, success is investigated as a performance-related function of individual factors after project termination such as e.g. meeting defined schedules, and commercial and customer objectives (Cooper et al., 2004b). However, especially for long-lasting and complex projects, it can be of importance to investigate more on factors from the initial to the maturing project phases as success and failure is often decided before the new product development (NPD) phase (Cooper, 1988). Examples would be the optimal initial team composition, team motivation over long time periods, or management support of complex innovations. Usually the innovator himself accompanies or leads the team from the original idea to the final concept and experiences the complete project period (Burger and Staake, 2010). With the innovator being aware of the project context, tendencies could be detected and turning points toward project success or failure, caused either by positive or negative influences on development teams, could be identified.

\subsection{MEMS and NEMS development environment}

The fields of microsystems, or MEMS, and nanosystems, or NEMS, are highly interdisciplinary, relying heavily on experimental activities from selection of materials, process validation, and design development to device characterization (Crone, 2008). Some prominent commercial examples of MEMS are Texas Instruments' Digital Mirror Device (DMD) (Douglass, 2003), Bosch's gyroscope for the Mercedes-Benz A-class adopted Elektronisches Stabilitätsprogramm (ESP) as standard equipment (Classen et al., 2007), or Infineon's pressure sensor (Scheiter et al., 1997). Examples of NEMS are IBM's 'Millipede' (Vettiger et al., 2002), Samsung's field emission display based on carbon nanotubes (CNTs) (Lee et al., 2000), or cantilever-based sensors in scanning probe microscopies (Li et al., 2007). For MEMS/NEMS the business and technical challenges are different from the classic semiconductor problems with longer design cycles, high cost per function, and slower time to market (Martin, 2010).

MEMS/NEMS provide an interface between computational reality and the surrounding environment by transforming physical quantities or perturbations through sensors and actuators (Ekinci and Roukes, 2005), through the use of electronic and nonelectronic elements on the microscale or nanoscale (Hierold, 2004). MEMS-based sensors are getting smaller with more functionality and are becoming smarter (Gornev, 2009). The application fields are diverse and vast. Typical application fields are the automotive industry, communication sector, consumer industry, health care, security, and environmental monitoring (Grace, 2000; Hierold et al., 2007; Crone, 2008). Diversity causes difficulties in creating coherent manufacturing processes, especially in the case of packaging, which often inhibits commercialization (Tadigadapa and Najafi, 2003; Tierney and Walsh, 2009; Martin, 2010). While MEMS technologies matured in the last 20 years, 
Table 1. Characteristics of microelectromechanical systems/nanoelectromechanical systems(MEMS/NEMS) development environment

\begin{tabular}{ll}
\hline Field & Characteristics \\
\hline Technology & Cross-sectional technology and \\
& combination of material, engineering, \\
and natural sciences. \\
New functionalities require know-how and \\
capabilities from function integration to \\
production and measuring/testing level \\
(Muller, 2000; Tadigadapa and Najafi, \\
2003). \\
Only a few standards in manufacturing \\
(Martin, 2010); no technology \\
roadmapping for MEMS/NEMS \\
(Kanama and Kondo, 2007) as for \\
semiconductors, e.g. International \\
Technology Roadmap for \\
Semiconductors (Arden, 2002). \\
Long development times $>5-15$ years or \\
more, e.g. Texas Instrument's DMD ${ }^{\mathrm{T} M}$ \\
(Douglass, 2003). \\
Broad application fields and \\
difficult-to-predict market development \\
(Tadigadapa and Najafi, 2003; Petersen, \\
2010). \\
MEMS devices are well established; \\
miniaturization (NEMS) is considered \\
to bring about new functionalities \\
and/or cost reductions (Hierold et al., \\
2007). \\
Long-term aspects have significant \\
influence on firm's investments and \\
product strategies (Maeda et al., 2007; \\
Tierney and Walsh, 2009). \\
Lack of know-how, experts, and \\
infrastructure due to vast opportunities \\
from development in material science \\
and nanotechnology (Bhushan, 2010). \\
Market
\end{tabular}

there still exist fundamental and technological challenges in NEMS, especially in developing reproducible techniques allowing mass production of such complex devices (Ekinci and Roukes, 2005). Moreover, technology maturity in MEMS technology resulted in a market adaptation from the former case of technology push toward that of market pull (Douglass, 2003; Vigna, 2005; Mounier and Eloy, 2007), requiring faster development cycles (e.g. Apple's iPhone and Nintendo's Wii console). Table 1 provides an overview of the MEMS/NEMS environment.

\subsection{Aim of this article}

This paper attempts to highlight managerial aspects on technology development teams in the early development phases of MEMS/NEMS innovations.
According to Cooper (1997), the early phases span the time frame between the idea stage and development stage, and refer to 'predevelopment' (Cooper and Kleinschmidt, 1993) or 'fuzzy frontend' (Khurana and Rosenthal, 1997) activities (see Figure 1). The study contributes to the sparse literature in the field of technology development projects and teams.

While most studies investigate research and development (R\&D) or innovation teams over all organizational branches, we attempt to develop a more practical and applied understanding of a specific organizational branch. The objective is to provide insights and to identify those factors that have major influences on the success of teams in MEMS/NEMS technology developments. In particular, the investigation focuses on innovators' experience on interdisciplinary and cross-functional teams (see Figure 2). Numerous studies focus on the identification of directly measurable single factors, e.g. setting of targets and milestones, market assessment and definition, salary increases and bonuses, etc. (Cooper and Kleinschmidt, 1987b; Ernst, 2002; Sun and Wing, 2005). However, the objective of this investigation is not to identify individual factors, which are directly related to the highest performance of development teams. There is a lack of studies that describe the more nonmeasurable and interrelated factors like personal linkage between leadership, know-how and experience, innovation drivers' characteristics, and market orientation in a long-term perspective. These aspects are the driving force for our investigation and qualitative research approach. Through a better understanding of these factors, innovation managers in MEMS/NEMS are better prepared to enhance organizational processes and the team environment for future MEMS/NEMS innovations.

\section{Background and past research}

NPD teams and interpersonal issues in organizations are depicted in a long and multifaceted history of studies. Several studies identified the following factors to be of importance for cross-functional development teams: leadership (McDonough, 2000; Stoker et al., 2001; Elkins and Keller, 2003), market and market entry (Cooper and Kleinschmidt, 1994; Brown and Eisenhardt, 1995; Hauser et al., 2006), team structure and culture (Cooper and Kleinschmidt, 1994; Cormican and O’Sullivan, 2004), innovation motivation (Galbraith, 1982; Amabile, 1997), innovation driver (Rothwell et al., 1974; Vojak et al., 2006), and vision and strategy (Zien and Buckler, 1997; Pearce and Ensley, 2004; Cooper 


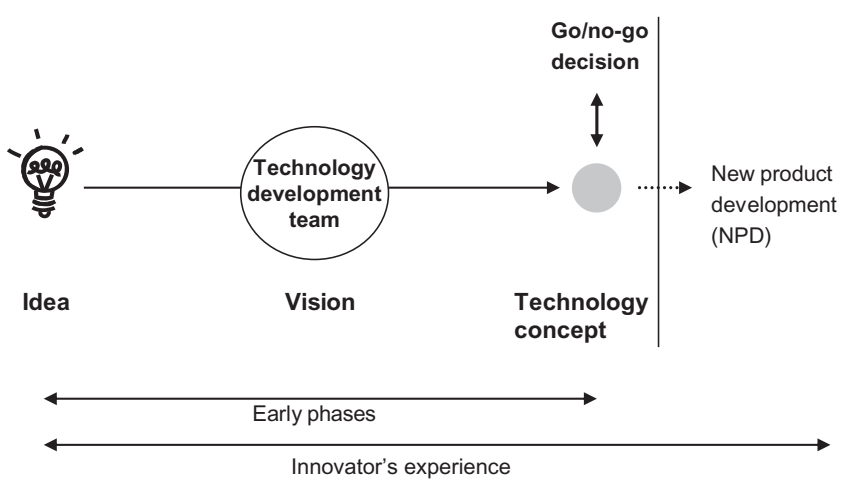

Figure 1. Early phases of innovation process (adapted from Khurana and Rosenthal, 1997).

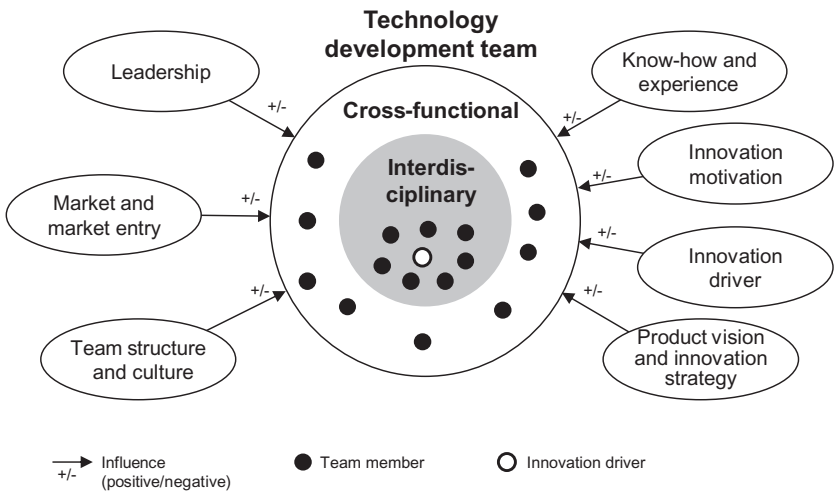

Figure 2. Microelectromechanical systems/nanoelectromechanical systems (MEMS/NEMS) team structure and major influences on technology development teams.

et al., 2004a). Only a few studies of technology development teams examined the creation of interdisciplinary know-how and experience, which were often cited by our interview partners. We will explore this issue additionally in our study. Figure 2 provides an overview of the studied influencing factors on technology development teams.

\subsection{Leadership in development project teams}

Even though the leadership's core task is clear strategy definition and communication (Porter, 1996), leadership has to shape and guide the project teams' tasks. Barczak and Wilemon (2003) point out that the team leaders' tasks are communication, climate setting, planning, and interfacing. Roberts and Fusfield (1981) found that leadership behavior plays a critical role in idea generation, entrepreneurship, or championing. In that case, the major purposes of leadership are the attainment of resources, selling ideas, project leading, and gatekeeping through information dissemination and personnel coordination, including sponsoring or coaching.
Technology in its early phases of development is often complex and fuzzy. Several studies indicate that transformational leadership with an inspirational vision and stimulation is a positive influence (Harris and Lambert, 1998; Elkins and Keller, 2003; Keller, 2006; Dayan et al., 2009). Looking at individual team members, Gemmill and Wilemon (1994) found that leadership has to carefully diagnose the personal attitude of members and their fears toward the development project. However, fears often arise through differences of perception, lack of communication, and an overly hierarchical leadership style. Norrgren and Schaller (1999) observed that the leadership style is important for the employee's climate perception and learning possibilities in cross-functional teams.

It is widely agreed that strategic leadership of technological innovations, where top management has demonstrated commitment from the idea stage to product launch, will have a high level of success (Cooper and Kleinschmidt, 1987a; Green, 1995; McDonough, 2000). Harris and Lambert (1998) studied the senior management's role in teams and found that the company's key practices and characteristics like clarifying responsibilities, team-to-team 


\section{Norbert Burger, Thorsten Staake, Elgar Fleisch and Christofer Hierold}

coordination, conflict resolution, organization of information flow, and access to resources are of importance for success.

With respect to the high uncertainty of technology projects (Cooper, 2006), our research attempts to illustrate what leadership characteristics and measures are necessary for complex and long-lasting technology development projects with a heterogeneous team composition.

\subsection{Market know-how, market entry}

It is widely agreed that the understanding of the customer's needs, his satisfaction, and internal and external communication and customer contact is related to the success of new products (Calantone and Cooper, 1981; Cooper and Kleinschmidt, 1993; Ragatz et al., 1997; Cooper, 1999; Hauser, 2001). However, little research has examined the team's role when the market is highly uncertain and market entry is far in the future.

For 'really new' product visions, Veryzer (1998) observed that a good sense of the technology and a general sense for the product application of the technology is required. Zirger and Maidique (1990) found that the competence of a company's marketing, its competitiveness, and the growth rate of the market has a positive influence on product success. Cooper and Kleinschmidt (1987a) demonstrated that products entering large and growing markets were more likely to be successful. Brown and Eisenhardt (1995) suggest that well-defined target markets have a significant influence on success.

MEMS/NEMS commercialization is delicate because of long development cycles as underlying basic science is not available or not yet well understood (Senturia, 2003; Fujita, 2007). Thus, the right time to market is a very critical point, as rival technologies will also be commercialized. The market entry is often far in the future, and the entry itself is very often a strategic action (Hauser et al., 2006). Our research seeks to explore reasons why market orientation for MEMS/NEMS is a highly anticipatory process.

\subsection{Team skills, composition, structure, and culture}

Many studies indicate that development teams with a certain skill mix are likely to be more successful (Cooper and Kleinschmidt, 1987a; Lewis, 2001; Rivas and Gobeli, 2005; Edmondson and Nembhard, 2009). Other studies examined interpersonal networks and communication skills, and their role in transforming personal knowledge to shared knowl- edge and communication within the business unit or corporate and external networks (Kogut and Zander, 1992; Moenaert and Caeldries, 1992; Nobel and Birkinshaw, 1998). Apart from technical competencies, team members' skills in fostering interpersonal climates, communication, and team process learning (Moenaert and Caeldries, 1992; Edmondson, 1999; Edmondson, 2003; Vojak et al., 2006) are of importance in developing visionary concepts (Vojak et al., 2006).

To solve such complex problems as those found in MEMS/NEMS, research suggests cross-functional teams to be crucial (Cooper and Kleinschmidt, 1994; Griffin, 1997; Ragatz et al., 1997; McDonough, 2000). Cross-functional teams consist of different functional areas of the company, providing the opportunity for a timely integration of critical information such as increased access to new knowledge and information, high-quality learning experiences, and facilitated interdepartmental product transfer (Edmondson and Nembhard, 2009). Little research has examined teams of technology development projects where the technology's solution approach is difficult to separate into the classical scientific disciplines (Beneke, 2004). Nanotechnology as a cross-sectional technology and basis for NEMS shows a high degree of different disciplines to be integrated for problem solving (Porter and Youtie, 2009). Hence, MEMS/ NEMS team structure is critical and has an influence on solution competencies of the team, but also on the product's success in the long run.

MEMS/NEMS technology development teams often need several years to understand technical interactions (Douglass, 2003; Dudley et al., 2003). Such time frames require an organizational and team culture to anchor the development in the organization. Cormican and O'Sullivan (2004) suggest that organizational culture can be described in terms of values, norms, and beliefs when members are sharing ideas, take risks, and initiate change. Other research suggests that the creation of a helpful culture within the team is of advantage, where members freely distribute and share information and practices (Rivas and Gobeli, 2005). Ahmed (1998) concludes that the most innovative companies of the future will be those that have created appropriate cultures that nurture and acknowledge innovation at every level. Thus, managerial practices should lead to an open and participative culture where employees have strategic and operational autonomy to attack problems by providing personalized recognition, focusing on group cohesiveness, and maintaining continuous slack resources (Judge et al., 1997).

Our research seeks to reduce the dearth of studies of teams in long-term technology projects. We do this 
especially by asking why technology development team members' competences and personal characteristics have to be carefully selected and adapted to the complexity of MEMS/NEMS.

\subsection{Innovation motivation (organizational, personal)}

The company's greatest innovation motivation is to save time and money (Rivas and Gobeli, 2005), gaining future competitive advantages (Mabert et al., 1992; Mudambi et al., 2007) and defending them against market entries of competition (Hauser et al., 2006). From the technology side, this is primarily done through miniaturization and high-volume products (Tierney and Walsh, 2009; Vigna, 2009; Martin, 2010). However, from the organizational side, Sherman and Smith (1984) observed that the organization's structure undermines intrinsic motivation with a negative influence on employees' autonomy and freedom, caused by greater controls, formalization, and centralization. On the contrary, the key processes for innovation itself should be structured (Galbraith, 1982; Cooper, 1999).

Amabile (1997) reviewed the work environment for creativity and concluded that intrinsic motivation is maximized through an interesting, involving, exciting, satisfying, or personally challenging and enjoying environment, but also negatively influenced through envy, vengeance, and altruism (Osterloh and Frey, 2000). Extrinsic factors, like financial rewards, allocation of resources, feedback, and information can foster intrinsic motivation. However, extrinsic motivation has a negative influence when this is perceived as criticism, control or an excess of formal structures or procedures (Amabile, 1997). For Osterloh and Frey (2000), intrinsic motivation is important for the transfer of tacit knowledge between teams as a competitive advantage, even though the transfer itself cannot be directly observed. Steiner (1995) found that the breakout from the structured thinking of traditional methods and the combination of novel interpretations that move their projects in new directions have a positive influence on team motivation. However, Lewis (2001) suggests to study the individual motivation carefully because of possible reputation and career prospects. As intrinsic motivation is more difficult to handle, organizations traditionally prefer a reward policy with 'carrots and sticks' (Argyris, 1998). It is widely agreed that awarding teams and individuals through personal and company-wide communicated awards is stimulative (Zien and Buckler, 1997) and has a positive influence on personal motivation. However, Griffin (1997) found in his study that best-practice companies do not use financial rewards. They used more teamrelated social activities like project-completion dinners, newsletter recognition, and plaques and pins as motivation.

We would like to show in our research that for MEMS/NEMS, the team's motivation requires a special focus to bridge the long period from idea to first technology concept.

\subsection{Innovation driver}

The innovation driver as a project leader or product champion has obviously an important role in technology development teams with a huge variety of required personal and professional skills (Brown and Eisenhardt, 1995). Literature proposes several types of human drivers in innovation teams: team leader (Barczak and Wilemon, 1992), project leader (Brown and Eisenhardt, 1995; Ernst, 2002), and product champion (Rothwell et al., 1974; Veryzer Jr, 1998; Howell and Shea, 2006). While team leaders and project leaders have more or direct access to the development team, resources, and budget, champions are decisive contributors or enthusiastic promoters of innovations. Ernst (2002) points out that it is not always clear whether the product champion is a different person from the project or team leader, and whether the promoting activities come from the official designated project leader or from other people in the organization. However, she or he must have the necessary qualifications, sufficient professional expertise, an inordinate interest, and to be able to devote her/himself sufficiently to the project (Chakrabarti, 1974; Howell and Higgins, 1990; McDonough, 2000). Edmondson (1999) and PirolaMerlo et al. (2002) found that drivers have a direct or indirect influence on success through the creation of a team climate with interpersonal trust and mutual respect. Brown and Eisenhardt (1995) observed that drivers have the cognitive ability to combine a variety of factors (e.g. technical and marketing skills, and customers preferences) to a holistic view - a vision and communicate it to others. Vojak et al. (2006) focused in his research on visionary leaders and suggest that a visionary leader is more than someone with technical and market know-how. He found that the personality with characteristics like persuasiveness, energy and enthusiasm, high self-esteem and self-assurance, but not arrogance, and passionate engagement for their projects supports success. Additionally, McDonough (2000) sees drivers as enablers who can act within different hierarchical levels of the organization and can facilitate the team's efforts.

Our research attempts to illustrate more thoroughly the personal characteristics and the origin 
from which technical directions innovation drivers in MEMS/NEMS come from, as little research is done in this direction.

\subsection{Know-how and experience (integrating expertise)}

The technology development team's combined know-how and experience has to cover a broad field of technological and business expertise. It is therefore crucial for companies to bring as much product, process, and technical expertise as possible into the early phases of the development process (Ragatz et al., 1997). From a technological standpoint, MEMS/NEMS integrate functions on a microscale or nanoscale, which requires technology competences from different scientific disciplines and collaboration (Schummer, 2004; Porter and Youtie, 2009). Thus, MEMS/NEMS are not an engineering direction (Senturia, 2003); it is rather a collection of technological capabilities that impact many disciplines from packaging and manufacturing (Tadigadapa and Najafi, 2003; Cordero et al., 2009), which should be covered by the technology development team.

Long development times of MEMS/NEMS technologies (Douglass, 2003; Senturia, 2003; Gornev, 2009) entail an interdepartmental anchorage of the project to accelerate progress. Expertise is required from several areas like engineering, production, marketing, and finance (Zirger and Maidique, 1990; Kogut and Zander, 1992; Denison et al., 1996; Griffin and Hauser, 1996; Song and Parry, 1997). Cummings (2004) found that team members actively engaged in external knowledge sharing increases success through unique external sources. For large international corporations, Nobel and Birkinshaw (1998) suggest strong internal- and external-oriented networks of relationships for knowledge exchange. Kash and Rycroft (2003) observed in the case of complex innovations due to great diversity and explosion of knowledge (e.g. Bosch's injection technology) organizational innovation networks as knowledge resources. However, the knowledge of individuals and ability to navigate the business world as an integrative factor is perceived as more important for success than most of the technical skills (Vojak et al., 2006).

In sum, integrating functions with MEMS/NEMS technologies for new products involves expertise from different technological and business fields. In this sense, our research seeks to explore the positive and misleading effects of expertise in MEMS/NEMS and how companies deal with the knowledge explosion and opportunities coming from nanotechnology.

\subsection{Product vision and innovation strategy}

A product vision should be a problem-solving, holistic view about business, project, technology, and product (Brown and Eisenhardt, 1995) from the idea to the customers (Zien and Buckler, 1997). Specific to product development, Brown and Eisenhardt (1995) suggest that the vision means combining the firms' competences (e.g. particular technical, particular marketing, or other skills) and strategies with the needs of the market to create an effective product concept. The team's major task is to work out such a concept. In this sense, Pearce and Ensley (2004) suggests that a vision has to be a shared purpose within teams. The vision plays a central role in the innovation process as it is a strong predictor for the team's altruistic and courtesy behavior, and it eliminates confusion. Hence, for the team's success the vision of the product functions, its purpose, and its target groups should be clear to all team members (Clark and Fujimoto, 1991).

The innovation strategy should define the objectives and targets of the product innovation effort in relation to the organization's overall business strategy (Bacon et al., 1994; Griffin, 1997; Cooper et al., 2004a). This includes markets, niche markets, and necessary structures for implementation (Cormican and O'Sullivan, 2004). Moreover, a long-term commitment to innovation (Cooper et al., 2004a) and a clear allocation of resources to gain sustainable competitive advantages is of importance (Shum and Lin, 2005). To realize innovation projects, Wheelwright and Clark (1994) suggest that the development team should have a deep customer understanding with clear and realistic project targets. Additionally, Khurana and Rosenthal (1998) suggest linking these targets with the overall development portfolio, while Cooper and Kleinschmidt (1996) assert that project targets have to fit the product strategy. However, for radical new products, the product strategy may also differ from the organization's strategy when the technical direction diverges through new technologies (Rice et al., 2001).

For MEMS/NEMS, market and technology is rather unpredictable. Our research attempts to show the function of the vision on technology development teams and effects of a wrong or missing vision in long-term projects.

\section{Research frame}

\subsection{Focus}

This investigation focuses on MEMS/NEMS technology development teams in the early development 
phases. The study differs from precedent researches on development teams and NPD as it brings the longterm experience of innovators in MEMS/NEMS and nanotechnology into focus. These people were a decisive force for initial ideas to be realized. Through their central function in innovation projects, they got the awareness of different levels and functions within their organization, had cross-links to middle and upper management, and had direct access to the development team. A further difference is the type of projects. The study concentrates on the development of new technologies. Often, the resulting technology is a platform for further products, processes, and technologies. The investigation focuses on a specific branch (see Table 1) where development teams sometimes have to work for years on a single specific technological problem. During this time, team members, technology, and market may change radically. Hence, innovators provide an accumulated and profound knowledge basis over the complete innovation cycle (see Figure 1).

Many studies of development teams analyze a specific team issue or focus on a specific project characteristic (Moenaert and Caeldries, 1992; O'Conner, 1998; Stoker et al., 2001; Pirola-Merlo et al., 2002; Camelo-Ordaz et al., 2008; Dayan et al., 2009), whereas our approach is to consider the experience of innovators from first ideas to a technology concept, covering several influencing aspects on development teams during this time. This approach is reflected in the open-ended questions, where innovators may recall all their experiences and identify the most likely factors that influence teams.

A research approach with an exploratory character allows us to access the innovators' knowledge basis, gaining important insights and attitudes into the factors that influence development teams most in the early development phases. By understanding these phenomena, we will be able to enhance our knowledge in analyzing actual implemented teams and to know better how to implement and manage development teams in MEMS/NEMS companies. The study will also help to understand the interactions between internal and external interfaces of the development teams, and issues influencing success.

\subsection{Origin and question}

This study on technology development teams was encouraged by the fact that technologies like MEMS/ NEMS and nanotechnology are critical to economic growth (Linton and Walsh, 2004; Spencer et al., 2008). MEMS/NEMS technologies require lateralthinking engineers with a breadth of skills and knowledge in different technologies (Vigna, 2003;
Newbert et al., 2008). From the technology side, MEMS/NEMS and nanotechnology are of disruptive nature (Walsh, 2004; Avila-Robinson and Miyazaki, 2011), which provide a further step toward miniaturization for cost reduction by new microstructures/nanostructures and increased functionality. Especially mechanical sensors based on CNT are an important driver for miniaturization (Hierold et al., 2007). Because manufacturing capabilities increased, technology moves from technology push to market pull (Vigna, 2005).

Time is an additional critical factor in commercialization as MEMS/NEMS technologies need up to 15 years or more to be established. A prominent example is Texas Instruments' DMD (Douglass, 2003). For such time frames, personnel constants are needed in technology development teams. Therefore, success seems to be personalized, whereat a small team or one person is the driver of innovation during such long time frames [e.g. DMD: Larry Hornbeck (Hornbeck, 1999), Bosch Process: Franz Lärmer and Andrea Urban (Laermer and Urban, 2005)].

By the examination of both positive and negative influences on development teams, we want to get a complete picture of the influences and to identify drivers and barriers. 'Positive' and 'negative' influences are meant in the sense of the innovator's personal assessment (Podsakoff and Schriescheim, 1985). The purpose of this subjective assessment was to identify phenomena and to experience what fosters and/or inhibits the technology development team's success. All interviewees had long job tenure and experiences in several innovation projects and teams. Therefore, the differentiation between positive and negative influences on development teams or projects was well developed by the interviewees.

The earlier mentioned aspects result in the guiding question of this investigation: How can technology development teams be managed more efficiently and effectively in the early phases of MEMS/NEMS innovations?

\subsection{Specific questions}

The specific questions asked to the innovators were:

1. Which kind of leadership has positive and negative influence on the team in the early phases?

2. What are the characteristics of MEMS/NEMS markets, and how can uncertainty be reduced?

3. Which team structure promises to be effective for technology developments in microsystems and nanosystems?

4. What is the driving force for MEMS/NEMS developments in the team and company? 


\section{Norbert Burger, Thorsten Staake, Elgar Fleisch and Christofer Hierold}

5. What are the major characteristics of an innovation driver to lead a development team to a successful concept?

6. Which experience and knowledge of team members are of importance for the early phases of microsystems and nanosystems?

7. What are the main characteristics of a product vision that fosters technological innovations in MEMS/NEMS?

\section{Methods and data}

\subsection{Research design and method}

The study uses a qualitative research approach by case studies based on interviews as a primary source of data. This allows interviewees to focus in-depth on significant fields and offers insights that quantitative data cannot easily reveal (Eisenhardt and Graebner, 2007). Following previous research specifications, the method allows us to identify the essence of the interviewees' experiences concerning a phenomenon (Creswell, 2003a). In our case, the experience refers to major influences on the management of teams of a technology development project over several years. Patton (2002) argues that a phenomenon of interest is lived experience that has to be carefully described how people perceive it, feel it, judge it, remember it, make sense of it, and talk about it with others. We consider this requirement by providing narrative quotes from interviewees.

The questions asked to the innovators were based on previous literature research on interdisciplinary and cross-functional development teams, on MEMS/ NEMS technologies, and on nanotechnology. Additionally, we also took discussions, the innovators' product and company presentation into consideration, where they pointed out particular project and team issues. Based on the identified issues, we generated a short questionnaire covering the major topics with the intention of a theoretical lens. The purpose of the short questionnaire was to narrow the field by the interviewee her/himself identifying the most important issues to be studied. Additionally, missing categories were supplemented, and finally the types of questions to be asked were shaped.

To investigate on and test the identified issues, we used the qualitative interview methodology. Qualitative data from questionnaires and interviews with the 'why' of what is happening are useful to understand the rationale or theory underlying relationships. Particularly, data from qualitative interviews may be used to ground an emergent theory outside of well established constructs. (Eisenhardt,
1989; Yin, 2009). Succeeding to the short questionnaire, semistructured in-depth interviews (Fowler Jr, 2009) involving multiple researchers have shown great benefit to see and examine the innovators' understanding of the studied issues (investigator triangulation) (Yin, 2009). Moreover, the interviewees were able to present their perspectives enriched by their long experience in technology developments in this field. The interviews allowed us to identify specific characteristics for MEMS/NEMS technology development teams by cross-analysis with data from previous discussions and literature research (data triangulation) (Yin, 2009).

Similar research methods with specific questionnaires and in-depth interviews were developed and tested by previous investigations in the field of product innovation and R\&D management (Karlsson and Ahlstrom, 1992; Denison et al., 1996; Farley and Rouse, 2000; Barczak and Wilemon, 2003; Thamhain, 2003; Lee and Kelley, 2008; Enkel and Gassmann, 2010).

\subsection{The sample}

We conducted in-depth interviews with nine innovators or R\&D managers from seven different multinational companies and one network organization in the field of MEMS/NEMS. As technology developments are rare, the companies and cases were intentionally, not randomly, selected. They were identified in the course of scientific exchange about microsytems and nanosystems innovations and research collaborations. The companies are well established and cover broad industry sectors with a wide field of applications. Because of long development times in MEMS/NEMS over several years (Douglass, 2003; Polla, 2010), the focus was chosen on innovators as respondents to cover a maximum time span of experience. The innovator's experience lasts from idea generation to a technology concept for a go or no-go decision by the top management and in most studied cases until a successful market introduction (see Figure 1).

Particular firms were chosen because of their long technology tradition and long experience in this field. In addition, their international leading position and successful innovations in MEMS/NEMS, and of course of their willingness to participate in this study, were criteria for selection. We focused on technology development projects that are fundamental for future products and processes, and where management decided to go ahead with further development or with mass production. The majority of these products or processes are already on the market or a respective market launch is foreseen in a few years. The average length of a technology 
Table 2. Profiles of studied organizations

\begin{tabular}{|c|c|c|c|c|}
\hline Name & Interviewee & Size & Industry sector & Core business of applications \\
\hline Company A & Innovator & Large & $\begin{array}{l}\text { Component manufacturer, } \\
\text { manufacturing processes }\end{array}$ & Sensors, automotive, security \\
\hline Company B & Innovator & Medium $^{1}$ & Component manufacturer & Sensors \\
\hline Company C & $\mathrm{R} \& \mathrm{D}$ manager & Large & $\begin{array}{l}\text { Basic research, component } \\
\text { manufacturer }\end{array}$ & $\begin{array}{l}\text { IT business, information and } \\
\text { communication }\end{array}$ \\
\hline Company D & $\mathrm{R} \& \mathrm{D}$ manager & Medium $^{1}$ & Materials and characteristics & Information and communication, imaging \\
\hline Company E & $\mathrm{R} \& \mathrm{D}$ manager & Large & Component manufacturer & Information and communication \\
\hline Company F & $\mathrm{R} \& \mathrm{D}$ manager & Large & System integrator, software & Information and communication, security \\
\hline Company G & Innovator & Large & System integrator & $\begin{array}{l}\text { Health care, life science, automation and } \\
\text { control, buildings }\end{array}$ \\
\hline Company $\mathrm{H}$ & Innovator & Medium-sized $^{1}$ & Component manufacturer & Sensors \\
\hline Company I & Manager & Micro $^{1}$ & MEMS, NEMS industry & Networking association \\
\hline
\end{tabular}

Note: Multinational companies that practice research and development in Germany, Austria, or Switzerland, but whose headquarter is not necessarily located in the mentioned country. Their production sites are partly in the mentioned countries, but also in the United States and Asia.

${ }^{1}$ Categorization according to the recommendation of European Commission [2003/362/EC] (Liikanen, 2003).

IT, information technology; MEMS, microelectromechanical systems; NEMS, nanoelectromechanical systems; R\&D, research and development.

development project from idea to concept was 5-10 years where the decision was made to continue development. Further details to studied companies and cases can be found in Table 2 .

\subsection{Interviews}

The interviews were designed to get specific insights into technology development processes, team constitutions, team dynamics, its interdisciplinary characteristics, and the cross-functional integration of teams in MEMS/NEMS organizations. Most of the projects referred to in the interviews were of retrospective character, while some projects were just before market launch. Confidentiality was granted to interview participants and participating organizations. The purpose of the narrative quotes is to anchor insights in a broader context. To meet confidentiality, all company information and quotes are anonymized.

The interviewees had a senior level position, with job tenure of more than 10 years in the respective company. They were either the inventor or innovator of a MEMS/NEMS product or process in their company, $\mathrm{R} \& \mathrm{D}$, or project manager with a leader function of the technology development team. Even though positive and negative influence on teams is of subjective nature, long job tenure and function enabled interviewees to discern immanent positive and negative influences on teams and personal differences. Their educational background was mainly from engineering or natural sciences, and they held different organizational functions and positions in their job tenure.

\subsection{Data collection and analysis}

Previous to the interviews with innovators, major categories were established from literature findings that reflected the research design. To increase reliability, data were obtained through different sources: (1) presentations and previous discussions with the innovators, complemented with official available information from scientific articles, and company and product presentations, (2) questionnaires based on intense literature research, focusing the interviews on major topics from innovator's perspective, and (3) in-depth retrospective interviews with an average length of $1.5 \mathrm{hr}$, which were tape-recorded, transcribed, and double-checked with interview partners for reliability (Bourgeois and Eisenhardt, 1988). Additional notes and observations were recorded during presentations, discussions, and interviews to receive a further, more distant view. The purpose of the combined data collection method was to structure the complexity of the study, getting a complete picture of the innovation itself, the technology development team, and insights into team dynamics and management processes.

According to Eisenhardt (1989), a combined data collection method from several sources is in particular useful for new and explanatory studies where a fresh perspective is needed, and which is considerably outside of the well-established theories and constructs. To identify causal interrelations between the type of technology project and management methods in the early phases of developments, we used crosscase analysis (Eisenhardt and Graebner, 2007). 


\section{Norbert Burger, Thorsten Staake, Elgar Fleisch and Christofer Hierold}

Table 3. Factors with substantial positive and negative influence on the success of technology development teams

\begin{tabular}{|c|c|c|c|c|}
\hline Influence & $\begin{array}{l}\text { Major positive } \\
\text { factors }\end{array}$ & Major positive attributes & $\begin{array}{l}\text { Major negative } \\
\text { factors }\end{array}$ & Major negative attributes \\
\hline 1 & Leadership (I) & $\begin{array}{l}\text { Definition of necessary } \\
\text { competences with respect } \\
\text { to technology's long-term } \\
\text { characteristics }\end{array}$ & $\begin{array}{l}\text { Team structure and } \\
\text { culture (III) }\end{array}$ & $\begin{array}{l}\text { Personal (e.g. career- } \\
\text { oriented) attitude and } \\
\text { missing team culture }\end{array}$ \\
\hline 2 & $\begin{array}{l}\text { Market, market } \\
\text { entry (II) }\end{array}$ & $\begin{array}{l}\text { Available market know-how } \\
\text { and right point of market } \\
\text { entry }\end{array}$ & $\begin{array}{l}\text { Market, market entry } \\
\text { (II) }\end{array}$ & $\begin{array}{l}\text { No market and wrong } \\
\text { market entry }\end{array}$ \\
\hline 3 & $\begin{array}{l}\text { Team structure and } \\
\text { culture (III) }\end{array}$ & $\begin{array}{l}\text { Team mix with experts, } \\
\text { politician, and } \\
\text { communicator; culture of } \\
\text { errors }\end{array}$ & $\begin{array}{l}\text { Wrong or missing } \\
\text { leadership (I) }\end{array}$ & $\begin{array}{l}\text { Leadership style (e.g. too } \\
\text { authoritarian) and lack of } \\
\text { management support }\end{array}$ \\
\hline 4 & $\begin{array}{l}\text { Innovation motivation } \\
\text { (IV) }\end{array}$ & $\begin{array}{l}\text { Company level: earning } \\
\text { sustainable money; team } \\
\text { level: idea realization }\end{array}$ & Innovation driver $(\mathrm{V})$ & $\begin{array}{l}\text { Missing driver; missing } \\
\text { persistency and missing } \\
\text { sure instinct }\end{array}$ \\
\hline 5 & Innovation driver $(\mathrm{V})$ & $\begin{array}{l}\text { Interdisciplinary thinker with } \\
\text { professional expertise }\end{array}$ & $\begin{array}{l}\text { Missing know-how and } \\
\text { experience (VI) }\end{array}$ & $\begin{array}{l}\text { No technology expert } \\
\text { networks; preconceived } \\
\text { ideas due to long job } \\
\text { tenure }\end{array}$ \\
\hline 6 & $\begin{array}{l}\text { Know-how and } \\
\text { experience (VI) }\end{array}$ & $\begin{array}{l}\text { Interdisciplinary know-how } \\
\text { from different engineering } \\
\text { and basic sciences, and } \\
\text { business experience }\end{array}$ & $\begin{array}{l}\text { Missing product vision } \\
\text { and innovation } \\
\text { strategy (VII) }\end{array}$ & $\begin{array}{l}\text { Lack of personal orientation, } \\
\text { technology and } \\
\text { manufacturing process } \\
\text { orientation }\end{array}$ \\
\hline
\end{tabular}

Note: Influence of factors according to aggregated codes of the interviewees' responses ( 1 = highest influence); multiple responses from interviewees are possible.

A qualitative content analysis was used to analyze the results of our interviews and data (Krippendorff, 1980; Mayring, 2008). To do this, we chose an inductive approach (Mayring, 2008) to transform interview transcripts into data that can be compared (Creswell, 2003b). To quantify interview data, interviewees' responses were coded to reflect the individual position and experience (Huberman and Miles, 1994). In the next step, a coding agenda was used and post hoc amended to analyze the text and identify common patterns (Krippendorff, 1980). The open-ended character of our specific questions offered free responses (Lebart et al., 1998), but also led to answers fitting often more than only in one particular category. In a further step, responses for each category were aggregated and summarized as absolute frequency (Krippendorff, 1980; Creswell, 2003b). The intensity of each category represents the priority of findings with most quotes (see Table 3). The following section presents the major findings of our study.

\section{Results and discussion}

Our exploratory analysis revealed six major positive and negative factors influencing development teams. Table 3 shows most cited factors with respective attributes. The number in brackets, e.g. (II), reflects the order of description in this section.

\section{(I) Leadership and management influence - fostering creativity and scope for development}

If innovation teams work on future MEMS/NEMS technologies with a high degree of uncertainty, then how can leadership influence this positively? According to the interviewees, the leaders' definition and redefinition of necessary competences and personalities plays a key role for success. One innovator notices on this:

As a team leader, it is necessary to define 'What competences do I already have in the team?' and 'What personalities do I have in the team?' and 'What is missing?' ... It has to be differentiated between the development of generations and evolutionary innovations. If we speak for example of MEMS 2020 or the 5th generation of a sensor then different people are requested.

This suggests that leaders should fill their team with individuals of a variety of disciplines (Barczak 
and Wilemon, 2003) with different skills and functions. The requested team members' competences may differ between future MEMS technology concepts and an NPD.

Interviewees indicated that the team cannot foresee '. . . how the world will develop as facts of technology and markets in such time horizons are quite difficult to predict'. A leadership style with characteristics like fuzzy control and giving someone his head was an often-noted reason for high positive influence on teams during the concept phase. The comment of one team leader reflects different authoritarian leadership influences in teams with its consequences:

A too authoritarian leadership style will definitely cause fears. This means that risk taking for new concepts will decrease due to fears of punishment if something fails. As a consequence, people will only take over low-risk activities which lead to small innovations. In that case a good mind-set for MEMS/NEMS innovations is to let the employees do what they think is the best, and a more authoritarian leadership style should be the mirror to externals of the team.

Additionally, leadership applying their management methods according to long-term projects of MEMS/NEMS technology developments through continuity in decisions, thinking and showing about the next steps of developments, was given as a positive reason for success. For some interviewees, on the contrary, the effectuation of such management methods does not always work because of company internal resistance. For those leaders, a team mix with different organizational functions helps to sweep resistance away.

Innovators frequently cited that the creation of an inspiring atmosphere and enthusiasm for the topic with the demonstration of impacts of innovation is indispensable in the early development phases. The impacts may show consequences for the employees themselves and the created competences to strengthen the company's competitive position in the long run. In contrast, the most frequently cited reason for a reduction of enthusiasm was the company's administration overhead, which has proven to be an innovation retarder and inhibitor.

The approval of organizational room for creativity and freedom of formation was a further aspect of positive leadership practices. Innovators noted that employees have to feel that her/his solution is accepted and her/his competence is acknowledged, and that she/he is not only a PowerPoint engineer.
Top management influence was an often-cited reason as a positive influence on the outcome of the team's concept. Innovators noted that the early phases and the innovativeness are influenced differently through the management levels. One innovator commented:

Many from the top management are extraordinary innovative and willing to take risks. Astonishing is that the innovativeness and willingness to take risks decreases in the middle and upper management. This does not exclude that they promote and demand innovation, but they do not live it up. Thus, there is sometimes a kind of a blockade between the company management level and the department management level which opposes against changes from top down and bottom up. And this hinders the readiness for innovations. Escalation processes, management meetings, and direct involvement of the top management help to bypass such situations which also reflect an honor to the team.

Technology and concept are in the early phases in a very fuzzy manner. Respondents commented that specifying and scrutinizing all statements at this stage of projects do not bring positive results. If the management questions the concept too much in detail, then results might be in general falsifications and assumptions become facts, which are actually no facts. On the contrary, a good story with substantiated facts behind where potential opportunities are shown is a good key for success.

On the whole, the findings suggest that leadership has to clearly deduce the innovation's requested competences and personalities for MEMS/NEMS developments. Leadership which is creating an inspiring atmosphere by showing enthusiasm for the technology and providing organizational room for technical creativity and freedom of development has a positive influence on the team. On the contrary, a too authoritarian leadership style increases fears and decreases the readiness for risk taking by team members. Risk taking in the development of new technology approaches can be increased when the management of all levels accepts technology fuzziness and by direct involvement of top management (Green, 1995).

(II) Market uncertainty and market entry a tightrope walk between missing acceptance and fluffed chance

When MEMS/NEMS market is highly uncertain, then what can be done to receive market information 
for nonexisting products and processes? For MEMS/ NEMS companies, market uncertainty is characterized through high product diversity with broad application fields of MEMS, converging technologies through miniaturization, and nonexisting production equipment for new technology concepts. These reasons for uncertainty that cause difficulties in the definition of product strategies and the meeting of market requirements were mentioned by most of the interviewees. Many interviewees noted that market studies are one source of looking into the future. However, they do not exist for new technology concepts as one project leader noted:

Product generations are in general planned. So, if there is a particular new generation of sensor products, there are considerations years in advance, about what the next generation will look like (e.g. with new functions), which is a real anticipating process. Market studies for radical innovations or innovations with a high degree of novelty do not exist.

How can the team then proceed to get market information? For two project leaders always the focus on both market and direct contact to potential (lead) customers (Cooper and Kleinschmidt, 1993) help to access market information:

We classify our ideas between the classic technologies and our new approach and see where our product fits. Sometimes, our products are too good and not needed. In the end, you have to take the phone and contact your direct customers, filtering their information and see if it fits and who can need this.

Leg work, leg work. You get out there and you talk to people. You ask people questions, you ask customers questions, you ask suppliers questions. What are they gonna develop us? Where do they see the market?

Additionally, interviewees mentioned the crossfunctional integration of experts like marketing champions into the team to ensure market-oriented development. Teams also accessed market information through scenario analysis, road mapping on products and processes, internal expertise, customers, competitors, and studies from academia. However, for the innovators, the long time horizon anticipates also a danger that there is finally no market. This was cited by all interviewees to be the highest risk for MEMS/NEMS technology development teams.

The time of entry, which was in the past influenced by a technology push where new functions were the driver of innovations, changed now toward market pull (Vigna, 2009). This resulted in a forced adaptation of market and product strategy of former mainly technology-oriented companies. Two innovators commented on this as follows:

For almost 10 years, we earned our money from that technology push topics, however this changes. The tendency is towards market pull which means that we have to orient ourselves to what the market wants. As the technology comes to maturity, innovations in microsystem technology have to meet market needs as the basic technology problems are solved.

$90 \%$ of the companies focus on the realization of their ideas in functions and technology. However, the interfaces like packaging and software are important for the feasibility and the readiness for the market, not only the function.

Market entry of MEMS/NEMS innovations is a strategic decision. Two project leaders commented about market entry, pricing, and necessary decisions:

Being too early results in market acceptance problems. But, also being too late is a fatal mechanism as then there will probably be prices on the market which have reached their economy of scale and which a market entrant cannot reach. Consequently, there is no way to escape, except it is a strategic decision to enter the market with two or three years of losses and then be in the market with respective profits.

You are pursuing an innovation, which is later not in great demand. Or the market continues into the right direction, but faster than anticipated. And you are completely too late. The delay results in too high entry level pricing that you cannot apply to join the market. I have the right idea, the right concept, but I am too late and my prices are too high.

Testing the market and the company's key customers with the technology concept in different stages accompanied by own market surveys was suggested by several innovators to prevent flops. In case the technology is of societal interest, two innovators see the presence in politics and governmental institutions, new standardization panels, and lobbying as a means to strengthen the technology's position in the early phases of developments.

In summary, the findings indicate that MEMS/ NEMS technology development teams have to face 
different uncertainties resulting from market and technology. First, market information for new technologies and resulting potential products do not exist. Second, necessary production equipment may not exist and may have to be developed. Third, the tendency to market pulls requires a closer market and customer orientation. The close market orientation is in contradiction to long development times. Therefore, the market entry results in a strategic decision with potential financial deficits. Market uncertainties can be reduced through continuous testing of both market and key customers with the new technology concept accompanied by own surveys and direct influence on stakeholders. Consistent with prior research, traditional methods like scenario analysis (Grant, 2008) and road mapping (Walsh, 2004; Laube and Abele, 2008) are used to reduce market uncertainties.

\section{(III) Team structure and team culture - a nucleus of basic and engineering disciplines}

If a team mix is beneficial (Edmondson and Nembhard, 2009), then what specific competences and personalities for MEMS/NEMS teams are needed? For technology problem solving of new functions and processes, all innovators cited a high degree of interdisciplinarity of scientific disciplines as a key for a successful team. One interviewee's comment reflects the cross-sectional technology characteristics of MEMS/NEMS and the necessity of thinking between and linking scientific disciplines:

In micro and nanosystems we do not pursue an engineering direction like mechanical engineering, which is rather uniform. Or the principles of electrical engineering and semiconductor electronics, which are rather limited disciplines. In micro and nanosystems technology one must be able to do something of everything. For this, chemistry is also very important.... One should also be ready to work oneself into semiconductor technology and signal processing or, e.g. how one can fabricate plastic packaging. This means in our case that the interdisciplinarity or the willingness to exceed some specific points which was learned in academia is very important.

Interviewees stated that the structure within a team should be complementary to the problem, which shall result in a matching picture for the technology development, otherwise '... if one makes mistakes in that case it will cost time, energy, and a lot of money'. Both, generalists and experts from different directions are needed in the team. However, team members play different roles as one innovator noted, 'the generalist is more a communicator and cannot replace specialists'.

Additionally, a personality mix was noted to be of high positive and negative influence for progress in the early phases. One innovator notes why a mix between freaks and politicians is of importance:

Technology freaks were often involved as lateral thinkers and producers of good ideas. We try to have up to one fourth of such freaks in our team.... They are very important for solution finding and new ways to go. But, sending them into hard discussions, then more porcelain could be smashed than puttied. Thus, for general political issues politicians should be sent.

More detailed regarding personalities, respondents also indicated that the personal attitude of team members toward the team (Barczak and Wilemon, 2003) and toward the technology itself can have a negative influence on the outcome. Two interviewees commented:

The personal attitude to the targeted innovation and team, e.g. career-oriented team members or too experienced members can lead the project to wrong directions and failure.

A team might not work when people are too introverted or too egoistic. This means that a real working team is necessary to operate in such a broad field like micro and nanosystems technologies. An attitude of focusing on career disturbs the long-term team building process.

Team culture was mentioned by several interviewees with a high positive and negative influence on the outcome of a new technology concept. This refers to the willingness for collaboration among experts, team building, and a sprit for democratic decisions. For interviewees, building a team culture depends also on team size and geographic distances. Some teams were located centrally (e.g. corporate technology), locally, regionally, or globally, which caused challenges in the team-building process.

A culture of errors was noticed by several innovators to be of positive influence on the result of technology developments as only 'Those who do not work make no errors - but, not working isn't ok at all'. The organization should create an innovation culture, where teams have the possibility to commit technical errors. For instance, two interviewees noted: 


\section{Norbert Burger, Thorsten Staake, Elgar Fleisch and Christofer Hierold}

Success is also built on failures, because I failed miserably again and again. In the corporate environment, there are so many boundaries and constraints playing a very significant role to bring somebody's invention to an unfulfilled dream.

I mean, look at the US. You are a good business man when you fail five times and then you have one success, but in Europe you are not given that chance. You don't get a second chance.

According to our data, a MEMS/NEMS team structure with a high degree of interdisciplinarity on functional and scientific discipline level and a personality mix promises to be effective. The structure between early phases and development phase can differ. Team members for innovative technology concepts have to be more creative and visionary rather than milestone oriented as in NPD. According to the innovators, technological creativity can be realized through a mix of cross-sectional technologists, generalists, politicians, lateral thinkers, technology freaks, or experts from basic and engineering sciences. Moreover, the team members' personal attitude may mislead the project. The attitude should focus on technology realization rather than on fast career steps. Combined, these results suggest that teams have to reflect technological complexity and long-term characteristics of the project in their structure. The request for a different team structure compared with NPD results from a high degree of technology uncertainty, varying ways of thinking due to different involved scientific disciplines, and geographical dispersion of expertise contributing to the team. Thus, teams creating a team culture and a culture of errors work more effective.

\section{(IV) Innovation motivation - earning sustainable money with impossible things}

What motivates companies and teams to work on a new technology approach over several years? Not surprisingly, the company's quintessential motivation for innovation is as one innovator noted, 'We would like to earn money - sustainable and on a long-term basis'. This is driven through global competition, price decreases, and increasing $R \& D$ and production cost for MEMS/NEMS. On the other hand, products have to be consequently better, providing more functionality, or cheaper.

For the team's intrinsic motivation, the organization itself may contribute in different ways. Several respondents noticed that possibilities for idea reali- zation and the demonstration of consequences from technology developments with added values have shown great influence on team members. One innovator made the following comment:

Somebody who has an idea should also see that his idea has been accepted and pulled through the end, and shows success. This motivates most of all. But, for this purpose budget is necessary.

The MEMS/NEMS technology itself and when '. . . something is impossible' to be realized technologically was commented to be of high influence on the team's motivation. Moreover, technological and organizational leeway fosters the motivation for innovative technology approaches as the following two interviewees commented:

Ideas come bottom up; they do not come from the CEO or by the boss in the innovation phase. Nobody told us 'You have to do that!'. We told our boss 'We would like to do that!'. And he said yes, because he might also have visions, but on another level.

An innovation climate should be created where people like to work, and where employees may think about topics which do not always fit into their scope of work.

The team members' resulting intrinsic motivation refers also to the possibility for experts to exchange experience and opinions internally (Osterloh and Frey, 2000) through expert networks and topical meetings. Additionally, flatten hierarchies where team members have the possibility to assess organizational levels equally were commented as a high influence on motivation.

Intrinsic motivation to work on a topic several years resulted also from the team composition. Innovation barriers for the team were those members who had low push and acted indifferently. Such a behavior is reflected through statements like 'Well, if the company does not want to, then they should stop' and arguments like 'Well, if my idea is not accepted, then the company should see where it will go without my idea'.

Extrinsic team motivation through different financial and nonfinancial methods and incentives was practiced by all companies. Innovators mentioned examples like nomination of the innovator of the year, special events for innovative employees, and participation in innovation programs. Furthermore, the winning of official prices for technologies and products in specific branches was mentioned of high 
positive influence on motivation as it may result in competitive advantages. However, companies finally focused on the nonfinancial methods for team motivation (Amabile, 1997).

In sum, motivation over long time frames is difficult, and teams experienced both intrinsic and extrinsic motivation. Precisely because MEMS/NEMS technology projects last over years, the technology itself and the idea realization with resulting business potentials is the most important engine of the teams' intrinsic motivation. Team members valuate technological and organizational leeway to be of high positive influence on their motivation. Extrinsic motivation through financial recognition has to be selected individually because of the mix of experts with individual preferences.

\section{(V) Innovation driver - an engineer with something of everything}

'Innovation wants to be fought for and those who drive it shall not climb down', was stated by one innovator. What then are the characteristics of somebody who has to drive MEMS/NEMS technology development projects over several years? For instance, one respondent from a large company commented on the required personal characteristics of an innovation driver:

Everybody who wants to drive innovation will encounter inevitably resistance - in ever large organization. Those who place themselves into the battle, these are at least people who are ready for criticism.

Personal characteristics like a high frustration tolerance was noted to be required to promote new MEMS/NEMS technology concepts because of the need of a long staying power. Personal attributes like stubbornness, persistency, and getting on the wrong side of somebody were cited as further necessary characteristics.

Functional characteristics include being an interdisciplinary thinker, a team player, and a motivator. She/he should be objective oriented and open for new ideas and having broad technological knowledge, but not necessarily being an expert. These characteristics were mentioned by several innovators to be of high positive influence on the teams' success. For instance, one respondent commented on the professional behavior of innovation drivers:

An idea is in the first stage just an idea, but it is the innovation driver's job to make the best of it. Some do not take the easy way out - they fight for it. They are seeking for allies and thinking about networks which could be supportive to the idea, and they energetically produce evidence why their idea is good.

According to the interviewees, the professional behavior refers also to know the business etiquette of the company and how to play with them.

Interviewees noticed that the innovation driver is very often the initiator of the idea, but she/he does not have to be the team leader by definition. The innovation driver's job tenure should not be too long to prevent a blinkered attitude to one's work. Note the comment from one project leader:

There is also a pain threshold - a taboo zone which may not be exceeded and needs intuition. If somebody is too long in the company, or if somebody has reached a higher position, then there is a tendency that people become cautious and risk-averse.

Innovation drivers are usually homegrown talents. It was frequently indicated that they come from academia known through joined (partially governmental) projects or common application and selection processes. Candidates from other companies are relatively rare. One interviewee provided some details to identify innovation drivers:

The majority usually enters the company after a university education or doctoral studies, perhaps with a short experience as post-doc in academia. These people in the first step are not the innovation drivers, but they could help the promotion of innovations. Typically, these innovation drivers come out of the engineering sciences like mechanical or electrical engineers and out of basic sciences like physics or chemistry.

Based on the interview data, it is suggested that the innovation driver's characteristics play a key role in interfacing the team and anchoring the technology development project within the organization (Hauschildt and Kirchmann, 2001). These characteristics (e.g. persistency and sure instinct) are needed on one hand to face expected resistance from different management levels, especially in larger organizations. On the other hand, the innovation driver has to bring impulses to the team to bridge the long period from idea to a technology concept. Classically, for MEMS/NEMS technology development teams, these people are experts coming from engineering or basic sciences with a willingness to take risks. 


\section{(VI) Know-how and experience - antagonism between necessary expertise and too preconceived ideas}

MEMS/NEMS and nanotechnology are crosssectional technologies, which require a high degree of different disciplines (Schummer, 2004). What know-how is then needed for MEMS/NEMS concepts? A lack of technological know-how from materials science and the integration of functions on chip level were cited by most of the interviewees to become a key weakness for companies. Several interviewees noticed that the team's access to technical know-how through internal and external networking (Rothwell, 1992) is of high influence for a successful concept. For instance, one innovator made following comment:

Technology is new and progressing fast. Some topics are always missing and the question is how to manage it. Therefore, inside and outside knowledge sharing networks and collaboration are necessary. You have to trust these people and at the end of the day, you pick up the phone and call them. However, a critical mass of experts should be in the company, as for sure, you cannot rely only on external experts.

Not surprisingly, for the respondents this network is growing with job tenure and position, while graduates still have to build up this network. But on the other hand, graduates bring in fresh ideas based on their experience.

Further sources for technology know-how were company internal experts who might come from a different business segment having solved similar topics. Opinions from external experts, e.g. from academia or research institutions, are important to reflect innovative ideas. One project leader noticed on this:

These future scenarios are mainly opinions and linked to competences of academia. Academic research groups do not only have an opinion where future technologies might go. In general, they also have technology approaches for potential solutions. If such opinions and capabilities include promising ideas for industrial solutions then companies are very interested in collaboration with academia.

Interdisciplinary knowledge was commented by all innovators to have positive influence on the efficiency of technology development teams. This refers to know-how from different engineering and basic sciences (e.g. mechanical engineering, chemistry, and physics) combined with business experience (e.g. national, international, different functions, and direct customer contact). Know-how is either transferred through licensing and joint projects mainly through doctoral students or by direct hiring of the knowledge carriers, whereas impulses for future topics are coming from customers, competitors, internal experts, and from publications (Lynn et al., 2000).

Interestingly, in contrast to necessary know-how from different fields, most innovators cited that too much experience can have negative influences on development progress. In fact, too much experience can lead to preconceived opinions and may block new innovative ideas. Note the comments from two interviewees:

Missing experience is the first step towards change. Thus, somebody with less experience probably develops a solution which another person with more experience does not think about. But, less experience can also mean to fall into traps where a lot of others have already trapped, which is of course dangerous. However, less experience can be balanced. In contrast, somebody with much experience is focused in one direction which is difficult to balance and to compensate.

Experience for me is two-minded. It is very helpful if somebody made experiences for years or made a lot of mistakes which should not be repeated. But, on the other side this experience (e.g. of gurus) is also hindering ideas. The team is corrective. I could tell you several examples, where people not directly related to the subject brought very good ideas. I would evaluate creativity and capability to be innovative in the concept phase as more important than experience.

The findings indicate that MEMS/NEMS technology development teams have generally a lack of technology know-how. Not surprisingly, this results from far-reaching visions with technology uncertainty, but also from the vast development of possibilities coming from material science and nanotechnology. Teams compensate this lack through inside and outside knowledge-sharing networks and collaboration. Surprisingly, the experience of team members is ambiguous. Experience is essential to prevent former technological mistakes. On the other hand, too much experience impedes that new ideas and new technology approaches are brought into the team. 


\section{(VII) Product vision and innovation strategy - the compass for long-term orientation}

A product vision should be a problem-solving, holistic view (Brown and Eisenhardt, 1995). What is then the function of the vision in MEMS/NEMS? The product vision for MEMS/NEMS technology development teams acts as orientation for future products, technologies, and processes, as market and technology are uncertain in the early development phases. This was mentioned by several innovators. One innovator made a comment on this:

The vision is the starting point ... with questions: 'What do I like to achieve in the future?', 'What do I like to change in the old world?'. And then they have to execute that passionately in order to drive towards that vision. So, the vision is also a target and without that you do not know where to go. Once you have got a good vision and once you have got a good strategy you find in most cases technologies, good tools, and processes. The vision and strategy are enablers to get there.

On the contrary, when a vision is missing the team is disoriented and is mislead to copy other technologies. Innovators noticed that product visions have to be far reaching because of high uncertainty in the early phases. Considering only short time horizons will limit the degree of innovativeness. When there are no time limits, the vision may allow fundamentally new products or processes.

Interviewees commented that visions were often set by the management or innovators. In order to reduce risks and failures by the team, it was noticed to test the vision in the market and adapt it:

You need to somehow test that vision. So, the vision often is the decision of where the boss wants to go. And it depends whether he is a good or bad boss or whether he is a visionary or whether he is misconceived.

Interviewees stated that the innovation strategy has to be long term oriented. Usually, companies request a short term for the return on investment (Tierney and Walsh, 2009). Consequently, the complete R\&D cost will be allocated on one generation, which increases pricing and may lead either to a strategic product or a flash in the pan. For instance, one innovator noticed:

If you enter the market with a new technology or a radical innovation, then one have to think in road maps and on a long-term basis. And, when the financier is not willing to think on a long-term basis then hands off.

Our findings indicate that a clear product vision in the early phases provides orientation to the team in MEMS/NEMS technology development and market orientation. A long-term orientation of the product vision and strategy is of positive influence for fundamental new technologies and future market positioning. It is further suggested that MEMS/NEMS technology development teams should frequently test and adapt their vision to reduce risks of dead ends later in the project. However, innovators also indicate a double bind of market orientation as pure market orientation with, e.g. short time horizons is limiting the degree of innovativeness.

\section{Conclusions}

New ideas from MEMS/NEMS and nanotechnology increasingly leave lab status as manufacturing capabilities on microscale and nanoscale have improved. Companies continue to invest into design, new process technologies, and production facilities for the commercialization of MEMS (Vigna, 2009). At this, the management of highly interdisciplinary teams is critical to effect long-lasting technology developments in emerging fields of MEMS/NEMS and nanotechnology.

The purpose of this investigation was to explore how MEMS/NEMS technology development teams in the early development phases can be managed more efficiently and effectively. It was the objective to provide an understanding of the team in its organizational and technology environment. Thus, major positive and negative influences on technology development teams were investigated rather than identifying single factors showing the highest influence on performance.

The results of this research suggest that the most critical issue for technology project teams is the buildup of knowledge and capabilities in system integration and manufacturing. While, for example, in the pharmaceutical industry preclinical tests are decisive for further development (Gassmann and von Zedtwitz, 2003), this study indicates that scientific knowledge and capabilities that span multiple fundamental and engineering disciplines are crucial for new technology concepts in MEMS/NEMS. Knowledge and capabilities are basis for long-term competitiveness and the development of core competences (Prahalad and Hamel, 1990). The actual process of creating these competences (lived 
experience) is of critical importance for the team. Because fundamental technologies are not well understood in the early phases, the joint developed experience of building up integrative competences enables the team to react quickly to unexpected technological and market changes.

MEMS/NEMS technology developments are substitutive and disruptive to other technologies (Linton and Walsh, 2004; Walsh, 2004). An early diffusion of the vision with market testing and adaptation reduces uncertainties and risks of failures later in the product development. This implies also a failure culture, both in the organization and project team, where e.g. probing and learning is practiced and lessons learned processes prevent a repetition of failures. As a consequence, leadership's creation of a long-term creative work environment, where experts are allowed to realize their ideas and exchange their expertise within technology communities, sets the framework for success. For this purpose, the team member's individual motivation toward long-term projects and technology has to be carefully analyzed.

Leadership and team organization in large MEMS/ NEMS companies most likely reflect the companies' general way of managing technology development teams. However, the investigated companies show that the team structure and leadership style need to be adapted to the project's and technology's complexity. Thus, the team structure can differ between the early phases and later developments. Even though technology is highly complex where specific expertise is needed, focusing only on one expert may mislead the project in the early phases. Informal personal networks provide a knowledge source and offer a filter function of new technology approaches. Consequently, the identification of experts and securing temporary access to them is more important than having them in the team. This explains how a lack of know-how and experience by team members can be an opportunity for developing something new rather than a blocking element.

Overall, the research and development of microsytems and nanosystems require lateralthinking engineers. These are engineers who have a breadth of skills and knowledge in different technologies. To solve difficult technology problems, they have to be acquainted with different scientific and engineering disciplines such as e.g. materials, physics, and mechanical and electrical engineering. In other words, this means a shift from traditional single discipline-oriented thinking and management of developments (e.g. separation of technological problems into mechanical and electrical engineering) toward a multidiscipline thinking and management of
MEMS/NEMS project teams by approaching technological problems as a whole.

\section{Limitations and further research}

Although this study improves the understanding of the management of technology developments, there are several limitations. First, the selected research model is based on a qualitative approach. Perceptional data obviously have limits and can be biased through a personal, historical context (Creswell, 2009). Furthermore, interviews with team members on a broad basis would have completed the picture. We could not affect this as team members often changed during long development time and members of large companies were widespread in global organizations. However, validity is increased through triangulation by means of the collected archival data, publications, internal documents, and using openended interview questions (Eisenhardt, 1989; Yin, 2009).

The second limitation is the sample size. Even though sample size is consistent with many studies in NPD and innovation team studies (Buckler and Zien, 1996; Farley and Rouse, 2000; Cooper, 2005), it certainly has its limits for generalization. The results presented are just a beginning, which need both refinement and further testing in a larger sample and more additional methodologically and statistically rigorous data assessment. However, the sample size still remains to be the major challenge. Technology projects are rare and often of strategic importance for companies (Cooper, 2006) with difficulties to access project information and people for research purposes.

The third limitation is the company size and regional aspects. We focused our study on small-, medium-, and large-sized companies in middle Europe that already have an MEMS history. For smaller companies, and especially start-ups, the organizational settings and communication paths are different and play a minor part in comparison to large organizations. Moreover, there are significant differences in organizational culture, leadership practices, and team management between European, Asian, North American, and South American companies (Hofstede, 1991). Cultural aspects therefore limit geographical applicability of this investigation.

\section{References}

Abernathy, W.J. and Clark, K.B. (1985) Innovation: mapping the winds of creative destruction. Research Policy, 14, 3-22. 
Ahmed, P.K. (1998) Culture and climate for innovation. European Journal of Innovation Management, 1, 30-43. Amabile, T.M. (1997) Motivating creativity in organizations: on doing what you love and loving what you do. California Management Review, 40, 39-58.

Arden, W.M. (2002) The international technology roadmap for semiconductors - perspectives and challenges for the next 15 years. Current Opinion in Solid State and Materials Science, 6, 371-377.

Argyris, C. (1998) Empowerment: the emperor's new clothes. Harvard Business Review, 76, 98-105.

Avila-Robinson, A. and Miyazaki, K. (2011) Conceptualization and operationalization of emerging technologies: a complementing approach. Proceedings of PICMET '11: Technology Management in the Energy Smart World (PICMET), 1-12.

Bacon, G., Beckman, S., Mowery, D., and Wilson, E. (1994) Managing product definition in high-technology industries: a pilot study. California Management Review, 36, 32-56.

Barczak, G. and Wilemon, D. (1992) Successful new product team leaders. Industrial Marketing Management, 21, 61-68.

Barczak, G. and Wilemon, D. (2003) Team member experiences in new product development: views from the trenches. $R \& D$ Management, 33, 463-479.

Beneke, F. (2004) Produktentwicklung. Arbeiten in und mit verschiedenen Disziplinen - wozu? Brand, F., Schaller, F., and Harald, V. (eds), Transdisziplinarität, Bestandsaufnahme und Perspektiven Beiträge zur THESISArbeitstagung im Oktober 2003 in Göttingen. Göttingen: Universitätsverlag. pp. 79-92.

Bhushan, B. (2010) Springer Handbook of Nanotechnology. Berlin - Heidelberg: Springer.

Bourgeois, L.J., III and Eisenhardt, K.M. (1988) Strategic decision processes in high velocity environments: four cases in the microcomputer industry. Management Science, 34, 816-835.

Brown, S.L. and Eisenhardt, K.M. (1995) Product development: past research, present findings, and future directions. The Academy of Management Review, 20, 343-378.

Buckler, S.A. and Zien, K.A. (1996) The spirituality of innovation: learning from stories. Journal of Product Innovation Management, 13, 391-405.

Burger, N. and Staake, T. (2010) From micro to nanosystems: an exploratory study of influences on innovation teams. International Journal of Business and Economic Sciences, 2, 286-297.

Calantone, R. and Cooper, R.G. (1981) New product scenarios: prospects for success. Journal of Marketing, $\mathbf{4 5}$, 48-60.

Camelo-Ordaz, C., Fernández-Alles, M.D., and ValleCabrera, R. (2008) Top management team's vision and human resources management practices in innovative Spanish companies. International Journal of Human Resource Management, 19, 620-638.

Chakrabarti, A.K. (1974) The role of champion in product innovation. California Management Review, 17, 58-62.
Christensen, C.M. (1997) The Innovator's Dilemma: When New Technologies Cause Great Firms to Fail. Boston, MA: Harvard Business School Press.

Clark, K.B. and Fujimoto, T. (1991) The process of development: from concept to market. In: Product Development Performance: Strategy, Organization, and Management in the World Auto Industry. Boston, MA: Harvard Business School Press. pp. 109-110.

Classen, J., Frey, J., Kuhlmann, B., and Ernst, P. (2007) MEMS gyroscopes for automotive applications. In: Valldorf, J. and Gessner, W. (eds), Advanced Microsystems for Automotive Applications 2007. Berlin, Heidelberg: Springer. pp. 291-306.

Coates, T.T. and McDermott, C.M. (2002) An exploratory analysis of new competencies: a resource based view perspective. Journal of Operations Management, 20 , 435-450.

Cooper, P. (2005) A study of innovators' experience of new product innovation in organisations. $R \& D$ Management, 35, 525-533.

Cooper, R.G. (1988) Predevelopment activities determine new product success. Industrial Marketing Management, 17, 237-247.

Cooper, R.G. (1997) Fixing the fuzzy front end of the new product process. CMA Magazine, 71, 3-21.

Cooper, R.G. (1999) From experience - the invisible success factors in product innovation. Journal of Product Innovation Management, 16, 115-133.

Cooper, R.G. (2006) Managing technology development projects. Research-Technology Management, 49, 23-31.

Cooper, R.G. and Kleinschmidt, E.J. (1987a) New products: what separates winners from losers? Journal of Product Innovation Management, 4, 169-184.

Cooper, R.G. and Kleinschmidt, E.J. (1987b) Success factors in product innovation. Industrial Marketing Management, 16, 215-223.

Cooper, R.G. and Kleinschmidt, E.J. (1993) Screening new products for potential winners. Long Range Planning, 26, 74-81.

Cooper, R.G. and Kleinschmidt, E.J. (1994) Determinants of timeliness in product development. Journal of Product Innovation Management, 11, 381-396.

Cooper, R.G. and Kleinschmidt, E.J. (1996) Winning businesses in product development: the critical success factors. Research-Technology Management, 39, 18-29.

Cooper, R.G., Edgett, S.J., and Kleinschmidt, E.J. (2004a) Benchmarking best NPD practices - II. Research Technology Management, 47, 50-59.

Cooper, R.G., Edgett, S.J., and Kleinschmidt, E.J. (2004b) Benchmarking best NPD practices - III. Research Technology Management, 47, 43-55.

Cordero, R., Walsh, S.T., and Kirchhoff, B.A. (2009) Organization technologies, AMT and competent workers: exploring relationships with manufacturing performance. Journal of Manufacturing Technology Management, 20, 298-313.

Cormican, K. and O'Sullivan, D. (2004) Auditing best practice for effective product innovation management. Technovation, 24, 819-829. 


\section{Norbert Burger, Thorsten Staake, Elgar Fleisch and Christofer Hierold}

Creswell, J.W. (2003a) A framework for design. In: Research Design: Qualitative, Quantitative, and Mixed Methods Approaches. Thousand Oaks, CA: Sage Publications. p. 15.

Creswell, J.W. (2003b) Mixed methods procedures. In: Research Design Qualitative, Quantitative, and Mixed Methods Approaches. Thousand Oaks, CA: Sage Publications. pp. 208-225.

Creswell, J.W. (2009) Variation in theory use in qualitative research. In: Research Design: Qualitative, Quantitative, and Mixed Methods Approaches. Los Angeles, CA: Sage Publications. pp. 61-64.

Crone, W.C. (2008) A brief introduction to MEMS and NEMS. In: Sharpe, W.N. (ed.), Springer Handbook of Experimental Solid Mechanics. New York: Springer. pp. 203-228.

Cummings, J.N. (2004) Work groups, structural diversity, and knowledge sharing in a global organization. Management Science, 50, 352-364.

Dayan, M., Di Benedetto, C.A., and Colak, M. (2009) Managerial trust in new product development projects: its antecedents and consequences. $R \& D$ Management, 39, 21-37.

Denison, D.R., Hart, S.L., and Kahn, J.A. (1996) From chimneys to cross-functional teams: developing and validating a diagnostic model. Academy of Management Journal, 39, 1005-1023.

Douglass, M.R. (2003) DMD reliability: a MEMS success story. In: Ramesham, R. and Tanner, D.M. (eds), Reliability,Testing, and Characterization of MEMS/MOEMS II. San Jose, CA: SPIE - International Society For Optical and Photonics. pp. 1-11.

Dudley, D., Duncan, W., and Slaughter, J. (2003) Emerging digital micromirror device (DMD) applications. In: Urey, H. (ed.), Conference on MOEMS Display and Imaging Systems. San Jose, CA: SPIE - International Society For Optical and Photonics. pp. 1425.

Edmondson, A.C. (1999) Psychological safety and learning behavior in work teams. Administrative Science Quarterly, 44, 350-383.

Edmondson, A.C. (2003) Speaking up in the operating room: how team leaders promote learning in interdisciplinary action teams. Journal of Management Studies, 40, 1419-1452.

Edmondson, A.C. and Nembhard, I.M. (2009) Product development and learning in project teams: the challenges are the benefits. Journal of Product Innovation Management, 26, 123-138.

Eijkel, K., Hruby, J., Kubiak, G., Scott, M., Brokaw, J., Saile, V., Walsh, S., White, C., and Walsh, D. (2006) Commercial importance of a unit cell: nanolithographic patenting trends for microsystems, microfabrication, and nanotechnology. Journal of Microlithography, Microfabrication, and Microsystems, 5, 011014011016.

Eisenhardt, K.M. (1989) Building theories from case study research. Academy of Management Review, 14, 532550.
Eisenhardt, K.M. and Graebner, M.E. (2007) Theory building from cases: opportunities and challenges. Academy of Management Journal, 50, 25-32.

Ekinci, K.L. and Roukes, M.L. (2005) Nanoelectromechanical systems. Review of Scientific Instruments, 76, (061101), 1-12.

Elkins, T. and Keller, R.T. (2003) Leadership in research and development organizations: a literature review and conceptual framework. Leadership Quarterly, 14, 587606.

Enkel, E. and Gassmann, O. (2010) Creative imitation: exploring the case of cross-industry innovation. $R \& D$ Management, 40, 256-270.

Ernst, H. (2002) Success factors of new product development: a review of the empirical literature. International Journal of Management Reviews, 4, 1-40.

Farley, M.S. and Rouse, W.B. (2000) Technology challenges \& opportunities in the biotechnology, pharmaceutical \& medical device industries. Information Knowledge Systems Management, 2, 133-141.

Fowler, F.J., Jr (2009) Survey interviewing. In: Survey Research Methods. Thousand Oaks, CA: Sage Publications. pp. 127-142.

Fujita, H. (2007) Two decades of MEMS - from surprise to enterprise. 20th IEEE International Conference on Micro Electro Mechanical Systems - MEMS '07. Hyogo, Japan: IEEE, 1-6.

Galbraith, J.R. (1982) Designing the innovating organization. Organizational Dynamics, 10, 5-25.

Gassmann, O. and von Zedtwitz, M. (2003) Innovation process in transnational corporations. In: Shavinina, L.V. (ed.), International Handbook on Innovation. Oxford, UK: Elsevier Science. pp. 702-714.

Gebert, D., Boerner, S., and Kearney, E. (2006) Crossfunctionality and innovation in new product development teams: a dilemmatic structure and its consequences for the management of diversity. European Journal of Work and Organizational Psychology, 15, 431-458.

Gemmill, G. and Wilemon, D. (1994) The hidden side of leadership in technical team management. ResearchTechnology Management, 37, 25-32.

Gornev, E.S. (2009) Sensors are getting smaller, more functional and smart. Journal of Nano and Microsystem Technique, 18-28.

Grace, R.H. (2000) Commercialization issues of MEMS/ MST/micromachines: an updated industry report card on the barriers to commercialization. In: Gonglewski, J.D., Vorontsov, M.A., and Gruneisen, M.T. (eds), HighResolution Wavefront Control: Methods, Devices, and Applications II. San Diego, CA: SPIE - International Society for Optical and Photonics. pp. 1-6.

Grant, R.M. (2008) Industry evolution and strategic change. In: Contemporary Strategy Analysis. Malden, MA: Blackwell Publishing. pp. 281-282.

Green, S.G. (1995) Top management support of R\&D projects: a strategic leadership perspective. IEEE Transactions on Engineering Management, 42, 223-232.

Griffin, A. (1997) PDMA research on new product development practices: updating trends and benchmarking 
best practices. Journal of Product Innovation Management, 14, 429-458.

Griffin, A. and Hauser, J.R. (1996) Integrating R\&D and marketing: a review and analysis of the literature. Journal of Product Innovation Management, 13, 191215.

Hage, J., Jordan, G., Mote, J., and Whitestone, Y. (2008) Designing and facilitating collaboration in R\&D: a case study. Journal of Engineering and Technology Management, 25, 256-268.

Harris, R.C. and Lambert, J.T. (1998) Building effective R\&D teams: the senior manager's role. ResearchTechnology Management, 41, 28-35.

Hauschildt, J. and Kirchmann, E. (2001) Teamwork for innovation - the 'troika' of promotors. $R \& D$ Management, 31, 41-49.

Hauser, J., Tellis, G.J., and Griffin, A. (2006) Research on innovation: a review and agenda for marketing science. Marketing Science, 25, 687-717.

Hauser, J.R. (2001) Metrics thermostat. Journal of Product Innovation Management, 18, 134-153.

Hierold, C. (2004) From micro- to nanosystems: mechanical sensors go nano. Journal of Micromechanics and Microengineering, 14, S1-S11.

Hierold, C., Jungen, A., Stampfer, C., and Helbling, T. (2007) Nano electromechanical sensors based on carbon nanotubes. Sensors and Actuators A: Physical, 136, 51-61.

Hofstede, G. (1991) Cultures and Organizations: Software of the Mind. London: McGraw-Hill.

Hornbeck, L.J. (1999) A digital light ProcessingTM update - status and future applications. In: Wu, M.H. (ed.), Conference on Projection Displays V. San Jose, CA: SPIE - International Society For Optical and Photonics. pp. 158-170.

Howell, J.M. and Higgins, C.A. (1990) Champions of technological innovation. Administrative Science Quarterly, 35, 317-341.

Howell, J.M. and Shea, C.M. (2006) Effects of champion behavior, team potency, and external communication activities on predicting team performance. Group \& Organization Management, 31, 180-211.

Huberman, A.M. and Miles, M.B. (1994) Early steps in analysis. In: Allen, M. (ed.), Qualitative Data Analysis: An Expanded Sourcebook. Thousand Oaks, CA: Sage Publications. pp. 50-89.

Judge, W.Q., Fryxell, G.E., and Dooley, R.S. (1997) The new task of R\&D management: creating goal-directed communities for innovation. California Management Review, 39, 72-85.

Kanama, D. and Kondo, A. (2007) The limitations of the technology roadmap and importance of new management tools in science-based innovation: the case of nanotechnology in Japan. In: Helander, M., Xie, M., Jaio, M., and Tan, K.C. (eds), IEEE International Conference on Industrial Engineering and Engineering Management. Singapore: IEEE. pp. 2115-2119.

Karlsson, C. and Ahlstrom, P. (1992) The difficult path to lean product development. 2nd International Product
Development Management Conference on New Approaches to Development and Engineering. Gothenburg, Sweden: Elsevier Science. pp. 283-295.

Kash, D.E. and Rycroft, R.W. (2003) To manage complex innovation, ask the right questions. ResearchTechnology Management, 46, 29-33.

Keller, R.T. (2006) Transformational leadership, initiating structure, and substitutes for leadership: a longitudinal study of research and development project team performance. Journal of Applied Psychology, 91, 202210.

Khurana, A. and Rosenthal, S.R. (1997) Integrating the fuzzy front end of new product development. Sloan Management Review, 38, 103-120.

Khurana, A. and Rosenthal, S.R. (1998) Towards holistic 'front ends' in new product development. Journal of Product Innovation Management, 15, 57-74.

Kogut, B. and Zander, U. (1992) Knowledge of the firm, combinative capabilities, and the replication of technology. Organization Science, 3, 383-397.

Krippendorff, K. (1980) Analytical techniques. In: Kline, F.G. (ed.), Content Analysis: An Introduction To Its Methodology. Newbury Park, CA: Sage Publications. pp. 109-115.

Laermer, F. and Urban, A. (2005) Milestones in deep reactive ion etching. 13th International Conference on SolidState Sensors, Actuators and Microsystems. Seoul, South Korea: IEEE, 1118-1121.

Laube, T. and Abele, T. (2008) Technologie-Roadmapping zur Planung und Steuerung der betrieblichen Forschung und Entwicklung. In: Möhrle, M.G. (ed.), TechnologieRoadmapping Zukunftsstrategien Für Technologieunternehmen. Berlin: Springer. pp. 353-386.

Lebart, L., Salem, A., and Berry, L. (1998) Textual statistics: scope and applications. In: Ide, N. and Véronis, J. (eds), Exploring Textual Data. Dordrecht, the Netherlands: Kluwer Academic Publishers, pp. 14-15.

Lee, H. and Kelley, D. (2008) Building dynamic capabilities for innovation: an exploratory study of key management practices. $R \& D$ Management, 38, 155-168.

Lee, N.S., Choi, W.B., Yi, W.K., Jin, Y.W., Choi, Y.S., Jung, J.E., You, S.G., You, J.H., Lee, C.G., Cho, S.H., and Kim, J.M. (2000) The carbon-nanotube based fieldemission displays for future large and full color displays. International Microprocesses and Nanotechnology Conference. Tokyo, Japan: Business Center for Academic Societies Japan, 124-127.

Lewis, M.A. (2001) Success, failure and organisational competence: a case study of the new product development process. Journal of Engineering and Technology Management, 18, 185-206.

Li, M., Tang, H.X., and Roukes, M.L. (2007) Ultrasensitive NEMS-based cantilevers for sensing, scanned probe and very high-frequency applications. Nature Nanotechnology, 2, 114-120.

Liikanen, E. (2003) Commission recommendation concerning the definition of micro, small and medium-sized enterprises (2003/362/EC). Official Journal of the European Union, 46, 36-41. 
Linton, J.D. and Walsh, S.T. (2004) Integrating innovation and learning curve theory: an enabler for moving nanotechnologies and other emerging process technologies into production. $R \& D$ Management, 34, 517-526.

Lynn, G.S., Reilly, R.R., and Akgun, A.E. (2000) Knowledge management in new product teams: practices and outcomes. IEEE Transactions on Engineering Management, 47, 221-231.

Mabert, V.A., Muth, J.F., and Schmenner, R.W. (1992) Collapsing new product development times: six case studies. Journal of Product Innovation Management, 9 , 200-212.

Maeda, R., Takahashi, M., and Sasaki, S. (2007) Commercialization of MEMS and Nano Manufacturing. 6th International Conference on Polymers and Adhesives in Microelectronics and Photonics. Tokyo, Japan: IEEE, 20-23.

Maine, E. (2008) Radical innovation through internal corporate venturing: Degussa's commercialization of nanomaterials. $R \& D$ Management, 38, 359-371.

Martin, J. (2010) High-volume manufacturing and field stability of MEMS products. In: Bhushan, B. (ed.), Springer Handbook of Nanotechnology. Berlin - Heidelberg: Springer. pp. 1803-1833.

Mayring, P. (2008) Neuere Entwicklung in der qualitativen Forschung und der Qualitativen Inhaltsanalyse. In: Mayring, P. and Gläser-Zikuda, M. (eds), Die Praxis der Qualitativen Inhaltsanalyse. Weinheim: Beltz. pp. 7-19.

McDermott, C.M. and O'Connor, G.C. (2002) Managing radical innovation: an overview of emergent strategy issues. Journal of Product Innovation Management, 19, 424-438.

McDonough, E.F. (2000) Investigation of factors contributing to the success of cross-functional teams. Journal of Product Innovation Management, 17, 221-235.

Merz, P., Wagner, B., Dudde, R., and Benecke, W. (2009) MEMS Foundry - Erfordernisse und Herausforderungen. MikroSystemTechnik Kongress 2009. Berlin: VDE Verlag, paper 36.

Moenaert, R.K. and Caeldries, F. (1992) Architectural redesign, interpersonal communication, and learning in R\&D. 2nd International Product Development Management Conference on New Approaches to Development and Engineering. Gothenburg, Sweden: Elsevier Science, 296-310.

Mounier, E. and Eloy, J.C. (2007) New emerging MEMS applications. In: Maher, M.A., Stewart, H.D., Chiao, J.C., Suleski, T.J., Johnson, E.G., and Nordin, G.P. (eds), Conference on Micromachining Technology For Micro-Optics and Nano-Optics V and Microfabrication Process Technology XII. San Jose, CA: SPIE - International Society For Optical and Photonics. (64620C) pp. 64621-64627.

Mudambi, R., Mudambi, S.M., and Navarra, P. (2007) Global innovation in MNCs: the effects of subsidiary self-determination and teamwork. Journal of Product Innovation Management, 24, 442-455.

Muller, R.S. (2000) MEMS: Quo Vadis in Century XXI? Microelectronic Engineering, 53, 47-54.
Newbert, S.L., Gopalakrishnan, S., and Kirchhoff, B.A. (2008) Looking beyond resources: exploring the importance of entrepreneurship to firm-level competitive advantage in technologically intensive industries. Technovation, 28, 6-19.

Nobel, R. and Birkinshaw, J. (1998) Innovation in multinational corporations: control and communication patterns in international R\&D operations. Strategic Management Journal, 19, 479-496.

Norrgren, F. and Schaller, J. (1999) Leadership style: its impact on cross-functional product development. Journal of Product Innovation Management, 16, 377384.

O'Conner, G.C. (1998) Market learning and radical innovation: a cross case comparison of eight radical innovation projects. Journal of Product Innovation Management, 15, 151-166.

Osterloh, M. and Frey, B.S. (2000) Motivation, knowledge transfer, and organizational forms. Organization Science, 11, 538-550.

Patton, M.Q. (2002) Conceptual issues in qualitative inquiry. In: Qualitative Research \& Evaluation Methods. Thousand Oaks, CA: Sage Publications. pp. 104-107.

Pearce, C.L. and Ensley, M.D. (2004) A reciprocal and longitudinal investigation of the innovation process: the central role of shared vision in product and process innovation teams (PPITs). Journal of Organizational Behavior, 25, 259-278.

Petersen, K. (2010) MEMS in the coming decade. 5th IEEE International Conference on Nano/Micro Engineered and Molecular Systems (NEMS 2010). Xiamen, China: IEEE, 1-9.

Pirola-Merlo, A., Hartel, C., Mann, L., and Hirst, G. (2002) How leaders influence the impact of affective events on team climate and performance in R\&D teams. Leadership Quarterly, 13, 561-581.

Podsakoff, P.M. and Schriescheim, C.A. (1985) Field studies of French and Raven's bases of power: critique, reanalysis, and suggestions for future research. Psychological Bulletin, 97, 387-411.

Polla, D.L. (2010) N/MEMS R\&D technology strategy and management. IEEE International Conference on Management of Innovation and Technology (ICMIT). Singapore, $1-4$.

Porter, A.L. and Youtie, J. (2009) How interdisciplinary is nanotechnology? Journal of Nanoparticle Research, 11, 1023-1041.

Porter, M.E. (1996) What is strategy? Harvard Business Review, 74, 61-78.

Prahalad, C.K. and Hamel, G. (1990) The core competence of the corporation. Harvard Business Review, 68, 7991.

Ragatz, G.L., Handfield, R.B., and Scannell, T.V. (1997) Success factors for integrating suppliers into new product development. Journal of Product Innovation Management, 14, 190-202.

Rice, M.P., Kelley, D., Peters, L., and O’Connor, G.C. (2001) Radical innovation: triggering initiation of 
opportunity recognition and evaluation. $R \& D$ Management, 31, 409-420.

Rivas, R. and Gobeli, D.H. (2005) Accelerating innovation at Hewlett-Packard. Research-Technology Management, 48, 32-39.

Roberts, E.B. and Fusfield, A.R. (1981) Staffing the innovative technology-based organization. Sloan Management Review, 22, 19-34.

Rothwell, R. (1992) Successful industrial innovation: critical factors for the 1990s. R\&D Management, 22, 221-240.

Rothwell, R., Freeman, C., Horlsey, A., Jervis, V.T.P., Robertson, A.B., and Townsend, J. (1974) SAPPHO updated - project SAPPHO phase II. Research Policy, 3, 258291.

Scheiter, T., Kapels, H., Oppermann, K.G., Steger, M., Hierold, C., Werner, W.M., and Timme, H.J. (1997) Full integration of a pressure-sensor system into a standard BiCMOS process. EUROSENSORS XI Meeting. Warsaw, Poland: Elsevier Science, 211-214.

Schummer, J. (2004) Multidisciplinarity, interdisciplinarity, and patterns of research collaboration in nanoscience and nanotechnology. Scientometrics, 59, 425-465.

Senturia, S.D. (2003) Perspectives on MEMS, past and future: the tortuous pathway from bright ideas to real products. 12th International Conference on Solid State Sensors, Actuators and Microsystems, Transducers'03. Bosten, Massachusetts: IEEE, 10-15.

Sherman, J.D. and Smith, H.L. (1984) The influence of organizational structure on intrinsic versus extrinsic motivation. The Academy of Management Journal, 27, 877-885.

Shum, P. and Lin, G. (2005) A world class new product development best practices model. 3rd International Conference on Manufacturing Research. Cranfield, England: Taylor \& Francis, 1609-1629.

Song, X.M. and Parry, M.E. (1997) A cross-national comparative study of new product development processes: Japan and the United States. Journal of Marketing, 61, $1-18$.

Spencer, A.S., Kirchhoff, B.A., and White, C. (2008) Entrepreneurship, innovation, and wealth distribution: the essence of creative destruction. International Small Business Journal, 26, 9-26.

Steiner, C.J. (1995) A philosophy for innovation: the role of unconventional individuals in innovation success. Journal of Product Innovation Management, 12, 431440.

Stoker, J.I., Looise, J.C., Fisscher, O.A.M., and de Jong, R.D. (2001) Leadership and innovation: relations between leadership, individual characteristics and the functioning of R\&D teams. 1st International Dutch HRM Network Conference. Rotterdam, Netherlands: Routledge, 1141-1151.

Sun, H. and Wing, W.C. (2005) Critical success factors for new product development in the Hong Kong toy industry. Technovation, 25, 293-303.

Tadigadapa, S.A. and Najafi, N. (2003) Developments in microelectromechanical systems (MEMS): a manufac- turing perspective. Journal of Manufacturing Science and Engineering, 125, 816-823.

Thamhain, H.J. (2003) Managing innovative R\&D teams. $R \& D$ Management, 33, 297-311.

Tierney, R. and Walsh, S.T. (2009) Towards a metric management approach for multi-emerging technology based fabrication facilities. PICMET '09 - 2009 Portland International Conference on Management of Engineering \& Technology. Portland, Oregon, USA, 409-419.

Utterback, J.M. (1994) Mastering the Dynamics of Innovation: How Companies Can Seize Opportunities in the Face of Technological Change. Boston, MA: Harvard Business School Press.

Veryzer, R.W., Jr (1998) Discontinuous innovation and the new product development process. Journal of Product Innovation Management, 15, 304-321.

Vettiger, P., Cross, G., Despont, M., Drechsler, U., Durig, U., Gotsmann, B., Haberle, W., Lantz, M.A., Rothuizen, H.E., Stutz, R., and Binnig, G.K. (2002) The 'Millipede' - nanotechnology entering data storage. IEEE Transactions on Nanotechnology, 1, 39-55.

Vigna, B. (2003) MEMS Dilemma: how to move from the 'technology push' to the 'market pull' category? International Symposium on VLSI Technology, Systems and Applications. Hsinchu, Taiwan: IEEE, 159-163.

Vigna, B. (2005) More than Moore: micro-machined products enable new applications and open new markets. IEEE International Electron Devices Meeting 2005, Technical Digest. Washington, D.C.: IEEE, 3-10.

Vigna, B. (2009) MEMS epiphany. IEEE 22nd International Conference on Micro Electro Mechanical Systems, 2009. MEMS 2009. Sorrento, Italy: IEEE, 1-6.

Vojak, B.A., Griffin, A., Price, R.L., and Perlov, K. (2006) Characteristics of technical visionaries as perceived by American and British industrial physicists. $R \& D$ Management, 36, 17-26.

Walsh, S. (2002) International roadmap on MEMS, microsystems, micromachining and top down nanotechnology. MANCEF. Naples, Florida.

Walsh, S., Carr, W.N., Mados, H., and Narang, D.S. (1996) Commercializing MEMS - too fast or too slow? Chau, K.H. and Roop, R.M. (eds), Micromachining and Microfabrication Process Technology II. Austin, TX: SPIE. pp. 12-24.

Walsh, S.T. (2004) Roadmapping a disruptive technology: a case study - The emerging microsystems and topdown nanosystems industry. Technological Forecasting and Social Change, 71, 161-185.

Walsh, S.T. and Linton, J.D. (2011) The StrategyTechnology Firm Fit Audit: a guide to opportunity assessment and selection. Technological Forecasting and Social Change, 78, 199-216.

Wheelwright, S.C. and Clark, K.B. (1994) Accelerating the design-build-test cycle for effective product development. International Marketing Review, 11, 32-46.

Yin, R.K. (2009) Case Study Research Design and Methods. Los Angeles, CA: Sage Publications.

Zien, K.A. and Buckler, S.A. (1997) From experience dreams to market: crafting a culture of innovation. 
Journal of Product Innovation Management, 14, 274287.

Zirger, B.J. and Maidique, M.A. (1990) A model of new product development: an empirical test. Management Science, 36, 867-883.

Norbert Burger is working as a Business Development Manager at ABB Switzerland. He received his $\mathrm{PhD}$ within the Department of Management, Technology, and Economics at ETH Zurich, Switzerland. He holds a diploma in mechanical engineering from the University of Karlsruhe (TH), Germany. His research focuses on the management of microsytem and nanosystem innovations. Formerly, he was the Director of the Micro and Nano Science Platform at ETH Zurich, a competence center and network of scientists in the field of microtechnology and nanotechnology. Before working at ETH Zurich, he was with Siemens AG and Bosch $\mathrm{GmbH}$ for more than 8 years in different European countries holding different management positions.

Thorsten Staake is a director and postdoc at the Bits to Energy Lab, a joint research initiative of ETH Zurich and University of St. Gallen, Switzerland. Before joining ETH, Thorsten Staake spent 1 year as a visiting researcher at the Auto-ID Lab at the Massachusetts Institute of Technology and worked for 2 years at the Institute of Technology Management at the University of St. Gallen. He holds an MSc in electrical engineering from Worcester Polytechnic Institute, Massachusetts, United States and an engineering diploma from Darmstadt University of Technology. During his studies, he received scholarships from the Center for Interdisciplinary Studies in Technology and the Swiss National Science Foundation, and worked at Infineon Technologies, Clariant, and LSD GmbH.
Elgar Fleisch is Professor of information management at the Department of Management, Technology, and Economics, ETH Zurich, Zurich, Switzerland. $\mathrm{He}$ is also Professor of technology management and the Director of the Institute of Technology Management, the University of St. Gallen. He conducts research on information management issues in the ubiquitously networked world, including the dynamics of information systems in conjunction with business processes and real world problems. Prof. Fleisch is a member of several steering committees in research, education, and industry.

Christofer Hierold is Professor of microsystems and nanosystems at ETH Zurich since April 2002. Previously, he was with Siemens AG and Infineon Technologies AG, Germany, working on complementary metal-oxide-semiconductor-compatible microsystems and their commercialization. His major research at ETH Zurich is focused on the field of nanotransducers, new materials for microelectromechanical systems, and advanced microsystems. He has been serving in program committees of numerous scientific conferences; he is cochair of the Steering Committee of the European Conference on Solid-State Transducers (Eurosensors); and he is a member of the Steering Committee of the International Conference on Solid-State Sensors, Actuators and Microsystems (Transducers), and of the International Conference on Micro Electro Mechanical Systems (MEMS). He is member of the editorial boards of the IEEE/ASME Journal of Micro Electromechanical Systems and of the Institute of Physics Journal of Micromechanics and Microengineering, and he is a joint editor of WileyVCH's book series on Advanced Micro and Nanosystems. Christofer Hierold is member of the Swiss Academy of Engineering Sciences. 